outpatient endoscopy procedures. Gastroenterology 2010;139: 163-170.

14. Klein J, Huisman I, Menon AG, et al. Postoperative infection due to contaminated propofol. Ned Tijdschr Geneeskd 2010;154:A767.

\section{Availability of Automatic Water Tap in Hospitals in Bangkok, Thailand}

To the Editor-Pathogens can contaminate the environment and cause infections. In hospitals, contamination of the environment is frequent and expected. Toilets in hospitals are an area of concern. The high contamination rates of toilet tap handles or levers for manual flushing are reported in many publications. ${ }^{1,2}$ Toilet seats and handles are commonly found to be contaminated. ${ }^{1}$ A good "toilet design" is proposed that could help control the spread of nosocomial infection. ${ }^{3}$ To reduce the problem of contamination, toilets with hands-free automatic flushing mechanisms or water taps have been available for a few years. Here, the authors report a field survey of 180 toilets from 25 hospitals in Bangkok, Thailand. According to the survey, automatic hands-free flushing mechanisms were available in 65 toilets (36.1\%). Most of the toilets studied lacked automatic water taps and classic toilet tap handles are still in use. The findings are potentially important and not just of local interest. Numerous hospitals in many countries in the world may still use manual flushing mechanisms. Promotion of the automatic water tap in hospitals will help improve hand hygiene in healthcare workers, visitors, and patients and may help reduce the problem of possible pathogen transmission.

\section{ACKNOWLEDGMENTS}

Financial support. None reported.

Potential conflicts of interest. Both authors report no conflicts of interest relevant to this article.

\section{Sora Yasri, $\mathrm{MD}^{1}$ Viroj Wiwanitkit, $\mathrm{MD}^{2,3,4,5}$}

Affiliations: 1. KMT Primary Care Center, Bangkok Thailand; 2. Hainan Medical University, China; 3. Faculty of Medicine, University of Nis, Serbia; 4. Joseph Ayobabalola University, Nigeria; 5. Dr D. Y. Patil Medical University, Pimpri, Maharashtra, India.

Address correspondence to Sora Yasri, MD, KMT Primary Care Center, Bangkok, Thailand (sorayasri@outlook.co.th). Infect Control Hosp Epidemiol 2015;36(7):864

(C) 2015 by The Society for Healthcare Epidemiology of America. All rights reserved. 0899-823X/2015/3607-0029. DOI: 10.1017/ice.2015.74

\section{REFERENCES}

1. Casey AL, Adams D, Karpanen TJ, et al. Role of copper in reducing hospital environment contamination. J Hosp Infect 2010;74:72-77.
2. Bellamy K, Laban KL, Barrett KE, Talbot DC. Detection of viruses and body fluids which may contain viruses in the domestic environment. Epidemiol Infect 1998;121:673-680.

3. Breathnach AS, Cubbon MD, Karunaharan RN, Pope CF, Planche TD. Multidrug-resistant Pseudomonas aeruginosa outbreaks in two hospitals: association with contaminated hospital wastewater systems. J Hosp Infect 2012;82:19-24.

\section{Epidemiology of Antimicrobial Resistance in an Oncology Center in Eastern India}

The epidemiology of multidrug-resistant organisms has local, national, and global significance. ${ }^{1,2}$ In this study we describe the epidemiology of antimicrobial resistance from a new oncology and bone marrow transplantation center in eastern India. The method of antimicrobial susceptibility testing was per the Clinical Laboratory Standards Institute guidelines. Stool surveillance culture was performed according to the method described by Landman et al. ${ }^{3}$ An automated system (Vitek2; bioMérieux) and disc diffusion (Bio-Rad) were employed for antibiotic susceptibility tests. The data refer to the period from April 1, 2012, through March 31, 2013. The data came from 4,723 samples, 1,474 patients (inpatients and outpatients), and 1,965 bacterial and yeast isolates. Gram-positive bacteria were detected in $25 \%$ of isolates, gram-negative bacilli in $68 \%$, and yeasts in $7 \%$. Positivity rates for different sample types were blood culture, $15.2 \%$; urine, $33.3 \%$; respiratory samples, $57.9 \%$; pus, $65.8 \%$; and body fluids, $37.0 \%$. Stool samples for surveillance culture of multidrug-resistant organisms were positive in $35.1 \%$. In total $30.6 \%$ were positive by culture.

Among patients with various infections antibiotic susceptibility of coliform bacteria (Enterobacteriaceae family) showed a high level of resistance with extended-spectrum beta-lactamase prevalence of $72 \%$, carbapenem resistance in $23 \%$, and resistance to amikacin, gentamicin, piperacillin-tazobactam, and ciprofloxacin to be $26 \%, 49 \%, 48 \%$, and $71 \%$, respectively. Nonfermentative gram-negative bacilli (eg, Pseudomonas, Acinetobacter) showed $36 \%$ resistance to carbapenems, $35 \%$ to piperacillin-tazobactam, $35 \%$ to amikacin, $38 \%$ to gentamicin, and $43 \%$ to ciprofloxacin. Resistance to meropenem and resistance to third-generation cephalosporins such as ceftazidime (marker of extended-spectrum beta-lactamase production) were detected respectively in cultures of $30.6 \%$ and $64.2 \%$ of blood isolates, $27 \%$ and $66.2 \%$ of urine samples, $25.7 \%$ and $47.8 \%$ of respiratory isolates, and $18.1 \%$ and $50.0 \%$ of pus isolates. Antibiotic resistance in gram-positive bacteria was noted in only $12 \%$ of the isolates (eg, methicillin-resistant Staphylococcus aureus), and inducible clindamycin resistance was noted in $23 \%$ of isolates. Antifungal susceptibility testing of Candida species $(n=123)$ showed $14 \%$ resistance to fluconazole. Among 356 patients with bloodstream infections, 55\% were due to 